\title{
Pilot study on the effect of topical adrenergic medications on human Tenon's capsule fibroblasts in tissue culture
}

\author{
I A Cunliffe, C A McIntyre, R C Rees, I G Rennie
}

\begin{abstract}
Recent publications have suggested that the long term use of topical antiglaucoma medications may be detrimental to the outcome of trabeculectomy. In order to investigate this further, the effect of several adrenergic agents and a preservative on the proliferation and viability of human Tenon's capsule fibroblasts in tissue culture were examined. The following compounds were tested: adrenaline (Eppy $1 \%$ and pure adrenaline base 1\%, Smith \& Nephew Pharmaceuticals Ltd); dipivefrine hydrochloride (Propine 0.1\% and pure dipivefrine hydrochloride $0 \cdot 1 \%$, Allergan Ltd and Allergan Pharmaceuticals (Ireland) Ltd); benzalkonium chloride (pure benzalkonium chloride 0.01\%, Sigma Chemical Company Ltd); the two adrenaline based preparations were also tested in the presence of an antioxidant. None of the tested compounds stimulated the proliferation of fibroblasts. The commercial products tested, their pure compounds, and the preservative all inhibited proliferation and had toxic effects on the cells. In the presence of antioxidant, commercial Eppy and pure adrenaline base appeared to have less effect on proliferation and toxicity. These findings are discussed with reference to the outcome of trabeculectomy.
\end{abstract}

(Br F Ophthalmol 1995; 79: 70-75)

Trabeculectomy is currently the favoured surgical treatment for glaucoma. It controls intraocular pressure (IOP) in up to $97.5 \%$ of cases $^{1}$ and is the best method of controlling IOP over a 24 hour period. ${ }^{2}$ Several recent publication $\mathrm{s}^{3-6}$ have suggested that the long term use of topical antiglaucoma medications may have an adverse effect on the outcome of trabeculectomy. The exact mechanism by which this effect may be mediated is as yet unknown. It has been shown ${ }^{78}$ that there is an increase in the number of inflammatory cells and fibroblasts in the conjunctiva of patients on long term treatment. It may be that the medications in some way induce the proliferation of fibroblasts that leads to the increased surgical failure.

In this study we investigated the direct effect of one group of antiglaucoma medications on the proliferation and viability of human Tenon's capsule fibroblasts in tissue culture.

\section{Materials and methods}

TISSUE CULTURE

Ethics committee approval was granted for the study and patients gave their written informed consent. For these experiments, human Tenon's capsule fibroblasts were established in tissue culture from biopsies derived from three different eyes (three females, age range 57-77). The biopsies were taken from Tenon's capsule at the superior aspect of the globe at the end of routine cataract surgery. The biopsies were placed in tissue culture medium and transported to the laboratory. None of the eyes used in this study had received topical antiglaucoma medications.

The biopsies were washed twice in phosphate buffered saline (PBS) containing penicillin 1\% (Brittania Pharmaceuticals Ltd, Redhill, Surrey), streptomycin 1\% (Sigma Chemical Company Ltd, Poole, Dorset), and fungizone $1 \%$ (Gibco Life Technologies, Paisley, Scotland). They were then dissected and placed in a tissue culture flask in Dulbecco's modified Eagle's medium (DMEM) (Gibco Life Technologies, Paisley, Scotland) containing $10 \%$ fetal calf serum (FCS) (Advanced Protein Products Ltd, Briesly Hill, West Midlands), penicillin 0.1\%, streptomycin $0 \cdot 1 \%$, and fungizone $1 \%$. The biopsies were then incubated at $37^{\circ} \mathrm{C}$ in $5 \%$ carbon dioxide in a humidified air atmosphere. When the fibroblast cultures became confluent, they were detached from the flask using trypsin $0.25 \%$ and EDTA $0.02 \%$ and replated into $75 \mathrm{~cm}^{2}$ tissue culture flasks.

Before each experiment the cells were washed twice with PBS, incubated at $37^{\circ} \mathrm{C}$ in trypsin $0.25 \%$ and EDTA $0.02 \%$ for $3-5$ minutes until cells detached, washed by centrifugation at $230 \mathrm{~g}$ for 10 minutes in DMEM with $10 \% \mathrm{FCS}$, resuspended in serum free DMEM, and recentrifuged. The cells were then resuspended in serum free DMEM, and the number of viable cells determined using the trypan blue exclusion method. The cells were then diluted in DMEM with $10 \%$ FCS to a final concentration of $1 \times 10^{4}$ live cells per millilitre.

\section{DRUG PREPARATION}

Sterile, commercially available, preparations of Propine $0 \cdot 1 \%$ (Allergan Ltd, High Wycombe), and Eppy 1\% (Smith and Nephew Pharmaceuticals Ltd, Romford) were serially diluted in serum free DMEM.

Pure benzalkonium chloride was purchased from Sigma Chemical Company Ltd, and pure forms of dipivefrine hydrochloride and 


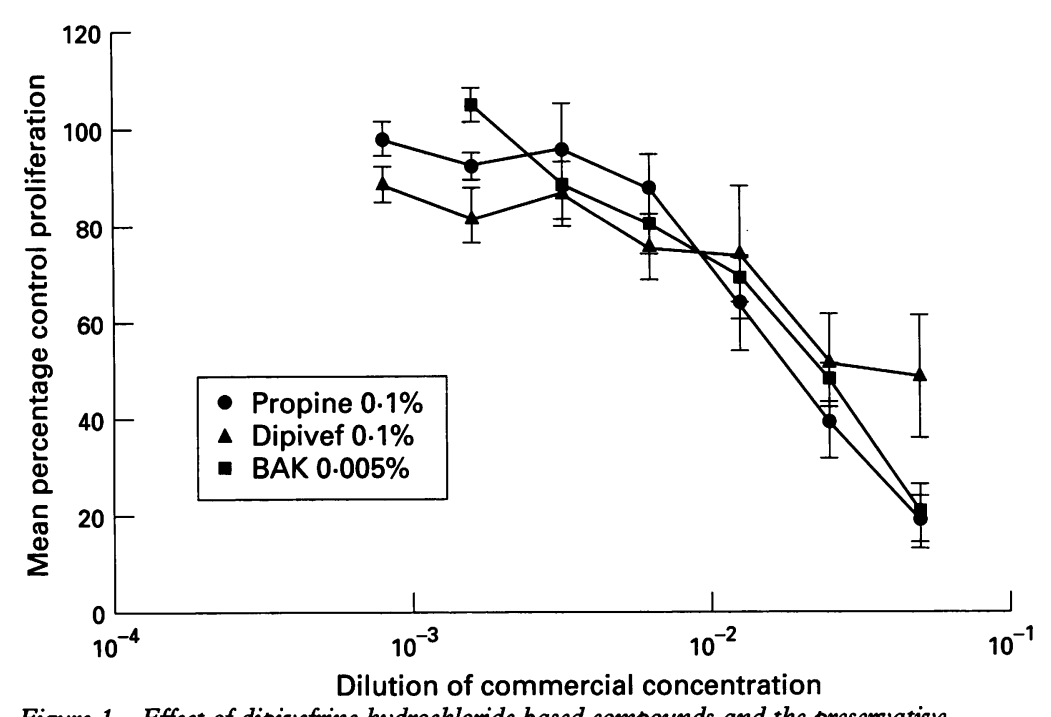

Figure 1 Effect of dipivefrine hydrochloride based compounds and the preservative benzalkonium chloride on the proliferation of human Tenon's capsule fibroblasts in tissue culture. Each point is the mean (SEM) percentage control proliferation of three experiments. Each experiment was performed on fibroblasts derived from different eyes, using three wells for each concentration. $B A K=$ benzalkonium chloride;

Dipivef=dipivefrine hydrochloride; Propine= commercial Propine.

adrenaline base were obtained from Allergan Pharmaceuticals (Ireland) Ltd and Smith and Nephew Pharmaceuticals Ltd respectively. The pure compounds obtained from the pharmaceutical companies had a certificate of analysis stating greater than $99 \%$ purity. These compounds were dissolved in water for injection to concentrations identical to those used in the commercial product and sterilised by filtration through a $0.22 \mu \mathrm{m}$ filter. They were then diluted in DMEM to make serial dilutions at the same concentrations as the commercial preparations. The dilutions chosen for use in these experiments were based on previous studies (unpublished data), which had shown that the range of dilutions over which benzalkonium chloride and dipivefrine hydrochloride compounds appeared to have maximum and minimum effects on proliferation was narrower than the range of dilutions for adrenaline

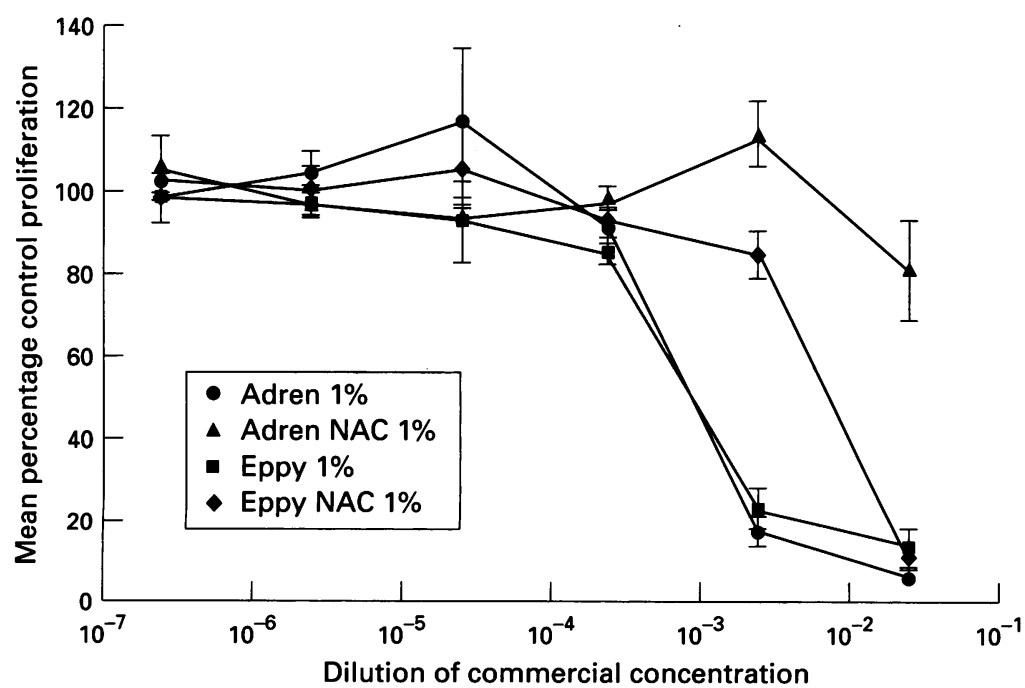

Figure 2 Effect of adrenaline based compounds with and without $\mathrm{N}$-acetyl-L-cysteine on the proliferation of human Tenon's capsule fibroblasts in tissue culture. Each point is the mean (SEM) percentage control proliferation of three experiments. Each experiment was performed on fibroblasts derived from different eyes, using three wells for each concentration. Adren=adrenaline base; adren NAC=adrenaline base with $\mathrm{N}$-acetyl-L-cysteine; Eppy =commercial Eppy; Eppy $N A C=$ commercial Eppy with $\mathrm{N}$-acetyl-L-cysteine. compounds. Therefore we were able to use doubling dilutions for dipivefrine hydrochloride, Propine, and benzalkonium chloride and 1 in 10 dilutions for adrenaline and Eppy. The effects of Eppy and pure adrenaline were also assessed in the presence of $N$-acetyl-Lcysteine $500 \mu \mathrm{g} / \mathrm{ml}$ (Sigma Chemical Company Ltd, Poole, Dorset) as an antioxidant. All drugs were filtered before addition to the medium and the $\mathrm{pH}$ of drugs in medium ranged from $7 \cdot 11$ to $7 \cdot 56$.

\section{PROLIFERATION STUDIES}

Proliferation experiments were performed without the use of antibiotics in the culture medium. One hundred microlitres of cells in DMEM with $10 \%$ FCS were dispensed into each well of a 96 well tissue culture plate. Cells were then incubated at $37^{\circ} \mathrm{C}$ in $5 \%$ carbon dioxide in a humidified air atmosphere. After 24 hours, $50 \mu l$ of drug in serum free medium and $50 \mu$ l of serum free medium containing $18.5 \mathrm{kBq}$ of ${ }^{3} \mathrm{H}$-thymidine were added to each well. Control wells received medium only. The plates were then incubated for a further 24 hours, when the cells were then harvested onto filter paper and the amount of ${ }^{3} \mathrm{H}$-thymidine incorporated into the cell DNA determined by scintillation counting. Each drug dilution was performed in triplicate. The mean value obtained for each drug dilution was divided by the control mean to give percentage control values. Experiments were repeated on cells derived from three different eyes, giving a total of three sets of results (one for each line).

Toxicity was assessed microscopically at 24 hours by two observers. Twenty four hours was chosen for toxicity assessment so that a correlation with the results of the proliferation assay could be made. Cell numbers were estimated by comparison with control wells, and the appearance of cells in culture was recorded. All photographs were taken using a Nikon phase contrast microscope with a $100 \times$ objective lens.

\section{Results}

\section{EFFECT OF ADRENERGICS ON FIBROBLAST} PROLIFERATION

None of the tested compounds stimulated the proliferation of Tenon's capsule fibroblasts in tissue culture. Scintillation counts for the three different lines ranged from 124-10 $196 \mathrm{cpm}$, $122-6561 \mathrm{cpm}$, and $250-6065 \mathrm{cpm}$ respectively. In order to allow for comparison between lines, the results were expressed as percentage control values. The dose-response curves illustrated are derived from the results of the three experiments performed, and each point shows the mean (SEM) of the three experiments.

The dose-response curves of pure dipivefrine hydrochloride, commercial Propine, and pure benzalkonium chloride all showed an inhibitory effect on proliferation at the higher concentrations tested, as shown in Figure 1. In this figure the benzalkonium chloride $0.01 \%$ effects are shown as the equivalent dilutions of 


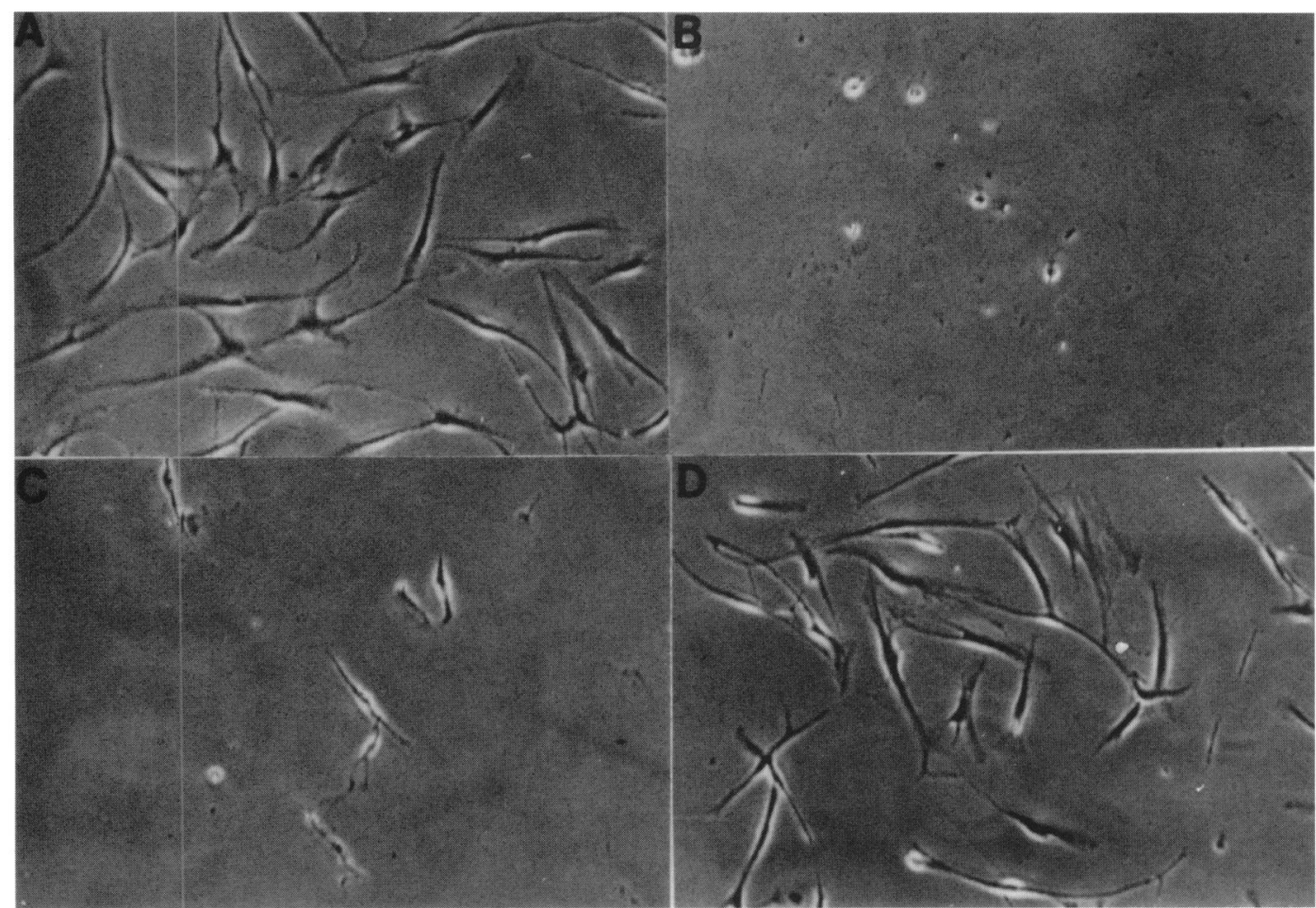

Figure 3 Photographs, using a Nikon phase contrast microscope, of cells on plastic tissue culture plates showing the effect of $(A)$ pure adrenaline base $1 \%$ at a 1:400 dilution with $\mathrm{N}$-acetyl-L-cysteine (control cells appeared similar); (B) pure adrenaline base $1 \%$ at a 1:400 dilution (mainly dead cells and cell debris); (C) commercial Eppy 1\% at a 1:400 dilution (mainly dead cells and cell debris); (D) commercial Eppy 1\% at a 1:400 dilution with N-acetyl-L-cysteine. Magnification $\times 60$.

$0.005 \%$ benzalkonium chloride to allow comparison with the commercial product which contains benzalkonium chloride at a $0.005 \%$ concentration. Pure dipivefrine hydrochloride, at the highest concentration used, may have been less inhibitory than commercial Propine and the pure preservative.

When pure adrenaline $1 \%$ and Eppy $1 \%$ were tested in the absence of $\mathrm{N}$-acetyl-Lcysteine they were both found to be inhibitory to fibroblast proliferation at the two highest concentrations tested (Fig 2). However, in the presence of $N$-acetyl-L-cysteine pure adrenaline appeared much less inhibitory at these two concentrations, as did the $10^{-2}$ dilution of commercial Eppy. Commercial Eppy in the presence of $\mathrm{N}$-acetyl-L-cysteine at the $10^{-1}$ dilution inhibited proliferation (Fig 2).

\section{EFFECT OF ADRENERGICS ON FIBROBLAST} VIABILITY

Representative photographs of cells in culture are shown in Figure 3. A summary of the effects of commercial Propine $0 \cdot 1 \%$, pure dipivefrine hydrochloride $0 \cdot 1 \%$, and pure benzalkonium chloride $0.01 \%$ on cells in culture is given in Table 1 . Table 2 gives the viability and appearance results for adrenaline base $1 \%$, adrenaline base $1 \%$ with $N$-acetyl-L-cysteine, commercial Eppy 1\%, and commercial Eppy 1\% with $\mathrm{N}$-acetyl-L-cysteine. In addition to the results presented in the tables, some brown discoloration of the wells was noted at the 1:40 and 1:400 dilutions of both commercial Eppy $1 \%$ and adrenaline base $1 \%$. No differences were noted between the control wells.

\section{Discussion}

Recently, several reports ${ }^{3-6}$ have suggested that the long term use of topical antiglaucoma medications may have an adverse effect on the outcome of trabeculectomy. Lavin et $a l^{3}$ showed that the number of preoperative medications was the largest single influence on

Table 1 Effect of dipivefrine hydrochloride based compounds and benzalkonium chloride on the viability of human Tenon's capsule fibroblasts in tissue culture compared with controls. Viability was estimated microscopically at 24 hours by comparison with control wells. The viability results are shown as the average of three experiments unless indicated

\begin{tabular}{|c|c|c|c|c|c|c|}
\hline \multirow[b]{2}{*}{$\begin{array}{l}\text { Drug } \\
\text { dilution }\end{array}$} & \multicolumn{2}{|c|}{ Propine $0 \cdot 1 \%$} & \multicolumn{2}{|c|}{ Dipivefrine hydrochloride $0 \cdot 1 \%$} & \multicolumn{2}{|c|}{ Benzalkonium chloride $0.001 \%$} \\
\hline & $\begin{array}{l}\% \\
\text { Viability }\end{array}$ & Appearance & $\begin{array}{l}\% \\
\text { Viability }\end{array}$ & Appearance & $\begin{array}{l}\% \\
\text { Viability }\end{array}$ & Appearance \\
\hline $1: 20$ & 15 & Shorter, thinner, loss of spindles & 35 & $\begin{array}{l}\text { Shorter, thinner, some } \\
\text { loss of spindles }\end{array}$ & $0^{\star}$ & All dead \\
\hline $1: 40$ & 45 & $\begin{array}{l}\text { Shorter and thinner with some loss of } \\
\text { spindles and granularity }\end{array}$ & 55 & Occasional thin cell & $5^{\star}$ & $\begin{array}{l}\text { Shorter, thinner, loss } \\
\text { of spindles }\end{array}$ \\
\hline $1: 80$ & 55 & $\begin{array}{l}\text { Shorter and thinner with some loss of } \\
\text { spindles and granularity }\end{array}$ & 60 & Occasional thin cell & $45^{\star}$ & $\begin{array}{l}\text { Shorter with some } \\
\text { loss of spindles }\end{array}$ \\
\hline $\begin{array}{l}1: 320 \\
1: 1280\end{array}$ & $\begin{array}{r}75 \\
100\end{array}$ & $\begin{array}{l}\text { Occasional thin cell } \\
\text { Healthy }\end{array}$ & $\begin{array}{l}75 \\
95\end{array}$ & $\begin{array}{l}\text { Healthy } \\
\text { Healthy }\end{array}$ & $\begin{array}{r}85^{\star} \\
100^{\star}\end{array}$ & $\begin{array}{l}\text { Occasional thin cell } \\
\text { Healthy }\end{array}$ \\
\hline
\end{tabular}

$\star$ Denotes results based on two experiments. 
Table 2 Effect of adrenaline based compounds with and without $\mathrm{N}$-acetyl-L-cysteine (NAC) on the viability of human Tenon's capsule fibroblasts in tissue culture compared with controls. Viability was estimated microscopically at 24 hours by comparison with control wells. The viability results are shown as the average of three experiments unless indicated

\begin{tabular}{|c|c|c|c|c|c|c|c|c|}
\hline \multirow[b]{2}{*}{$\begin{array}{l}\text { Drug } \\
\text { dilution }\end{array}$} & \multicolumn{2}{|c|}{ Adrenaline base 1\% } & \multicolumn{2}{|c|}{ Adrenaline base $1 \%+N A C$} & \multicolumn{2}{|c|}{ Commercial Eppy $1 \%$} & \multicolumn{2}{|c|}{ Commercial Eppy $1 \%+N A C$} \\
\hline & $\begin{array}{l}\% \\
\text { Viability }\end{array}$ & Appearance & $\begin{array}{l}\% \\
\text { Viability }\end{array}$ & Appearance & $\begin{array}{l}\% \\
\text { Viability }\end{array}$ & Appearance & $\begin{array}{l}\% \\
\text { Viability }\end{array}$ & Appearance \\
\hline $\begin{array}{l}1: 40 \\
1: 400\end{array}$ & $\begin{array}{l}0 \\
0\end{array}$ & $\begin{array}{l}\text { All dead } \\
\text { All dead }\end{array}$ & $\begin{array}{l}85 \\
95\end{array}$ & $\begin{array}{l}\text { Healthy } \\
\text { Healthy }\end{array}$ & 25 & $\begin{array}{l}\text { Shorter, thinner, loss of spin- } \\
\text { dles, some granularity }\end{array}$ & $15^{\star}$ & $\begin{array}{l}\text { Shorter, thinner, loss of } \\
\text { spindles }\end{array}$ \\
\hline & 0 & & & & 0 & All dead & $65^{\star}$ & Occasional thin, short cell \\
\hline $1: 4000$ & 35 & $\begin{array}{l}\text { Some shorter, with loss of } \\
\text { spindles and granularity }\end{array}$ & 100 & Healthy & $65^{\star}$ & Some cells shorter and granular & $95^{\star}$ & Healthy \\
\hline $1: 40000$ & 90 & Healthy & $100^{\star}$ & Healthy & 85 & Healthy & $100^{\star}$ & Healthy \\
\hline $1: 4000000$ & 100 & Healthy & 100 & Healthy & 100 & Healthy & $100^{\star}$ & Healthy \\
\hline
\end{tabular}

^Denotes results based on two experiments.

outcome of trabeculectomy, and previous exposure to sympathomimetics was also identified as a significant adverse factor. Hitchings ${ }^{9}$ has reported that on long term follow up, the group of patients in Lavin's study who were in the delayed surgery group (and so received long term preoperative topical therapy) have an increased failure rate with time. Miller et $a l^{4}$ have identified the prior use of topical antiglaucoma medications as an adverse factor for the outcome of trabeculectomy in congenital glaucoma. Batterbury and Wishart ${ }^{5}$ found that in their study the most important factor in determining the success of trabeculectomy in controlling IOP was the duration and number of prior topical medications, and Longstaff $e t a l^{6}$ have shown that the cumulative years of preoperative topical therapy was an adverse factor for pressure control after glaucoma triple procedures.

Trabeculectomy failure is usually due to subconjunctival fibrosis at the fistula site. The fibroblast is the pivotal cell in this process with three main functions in wound healing proliferation, migration, and synthesis. The control of these functions is the key to why some individuals are more at risk of enhanced wound healing than others. With respect to trabeculectomy the exact mechanisms by which the long term topical use of antiglaucoma medications may predispose to an increased risk of surgical failure are not fully known.

We have shown that none of the drugs tested at the given concentrations had a stimulatory effect on fibroblast proliferation. In contrast, most drugs had an inhibitory effect that was probably due to toxicity. Commercial Propine, pure dipivefrine hydrochloride, and benzalkonium chloride at the concentration used in Propine, all had similar inhibitory and toxic effects at the higher concentrations tested. Similarly, commercial Eppy and pure adrenaline base were inhibitory and toxic at the two highest concentrations tested. This effect may have been due to the oxidation of adrenaline to adrenochrome as a brown discoloration of some of the wells was noted. In addition, in the presence of $\mathrm{N}$-acetyl-L-cysteine as an antioxidant, pure adrenaline base did not significantly inhibit proliferation and the cells appeared healthy. Commercial Eppy, in the presence of $N$-acetyl-L-cysteine, was inhibitory and toxic at the highest concentration tested; however, this effect could be consistent with the presence of the preservative benzalkonium chloride in the commercial formulation. This suggests that one mechanism of toxicity of adrenaline may be mediated via its oxidation to adrenochrome, which is a well recognised clinical occurrence.

Microscopically, a 1:40 dilution of commercial Eppy appeared less toxic than a 1:400 dilution; this may have been due to the fact that commercial Eppy contains $N$-acetyl-Lcysteine which at the initial dilution may have still prevented some of the oxidation to adrenochrome, but at further dilutions was not at a high enough concentration to prevent this. Adrenochrome deposition has also been noted with commercial Propine and although discoloration was not noted in this study, the fibroblasts may have been able to convert the Propine into adrenaline with subsequent oxidation to adrenochrome resulting in toxicity.

Topical medications can have several clinically detectable effects on the conjunctiva, and the different mechanisms by which these can occur have been reviewed by Wilson. ${ }^{10}$ Use of topical adrenaline has been associated with several effects including burning, irritation, hyperaemia, allergic blepharoconjunctivitis, follicular conjunctivitis, adrenochrome deposits in the conjunctiva and cornea, and nasolacrimal obstruction. ${ }^{11-15}$ Use of dipivefrine has also been associated with burning, stinging, conjunctival hyperaemia, blepharoconjunctivitis, follicular conjunctivitis, and adrenochrome deposits in the conjunctiva and cornea. ${ }^{12-17}$ The preservative benzalkonium chloride has been implicated in the aetiology of papillary conjunctivitis, blepharitis and conjunctival hyperaemia, and allergic reactions. ${ }^{10} 18-20$

Conjunctival fibrosis and forniceal shallowing have been shown by Wright ${ }^{21} 22$ to be associated with the use of adrenergic agents and preservatives. Several authors ${ }^{23-26}$ have also described clinical cases of pseudopemphigoid changes in the conjunctiva of patients on topical medications including adrenergic agents. The mechanism by which this occurs is not known, but Fiore et al ${ }^{24}$ propose that drug induced ocular pemphigoid represents a spectrum of diseases ranging from a self limiting, toxic form to a progressive, immunological form. In a clinical study, Schwab et al ${ }^{27}$ have shown inferior forniceal shortening compared with controls in patients receiving miotic and non-miotic medications (including adrenergic agents) for a minimum of 3 years, and postulate this to be due to either the drug or the preservative. 
Sherwood et $a l^{7}$ have shown a significant increase in the number of tissue inflammatory cells and fibroblasts in the conjunctiva and Tenon's capsule of patients on long term antiglaucoma medications. Broadway et $a l^{8}$ have investigated this further by looking at biopsies from patients on different groups of medications ( $\beta$ blocker alone, $\beta$ blocker plus pilocarpine, and $\beta$ blocker plus pilocarpine plus sympathomimetic). Biopsies from patients on triple therapy ( $\beta$ blocker, pilocarpine, and a sympathomimetic) showed the greatest cellular changes in the conjunctiva, and these changes correlated with a poorer surgical outcome to trabeculectomy at 6 months' follow up. Broadway et al ${ }^{28}$ have also shown that by using topical fluoromethalone and curtailing the use of sympathomimetics for 1 month before trabeculectomy, the number of fibroblasts and inflammatory cells in the conjunctiva can be reduced. This was also associated with an increased success in trabeculectomy (as assessed by IOP control) at 1 year follow up, and may provide a simple method of overcoming some of the potential problems of long term topical treatment.

Brandt et $a l^{29}$ have shown significantly different degrees of conjunctival metaplasia (as measured by impression cytology) in patients on glaucoma triple therapy ( $\beta$ blocker, pilocarpine, and an adrenergic agent) compared with controls. Eyes receiving only a combination of $\beta$ blocker and an adrenergic agent had a cytological grade higher than controls but this was not statistically significant, and they postulate from this that some of the effects seen may be mediated through the adrenergic receptors. However, it is not known if these epithelial changes are indicative of subepithelial changes.

Several animal studies have tried to look at the effect of topical medications on the conjunctiva. With reference to adrenergic agents, Smith et $a l^{30}$ failed to show a statistically significant increase in inflammatory cells in the conjunctiva of rabbit eyes that had received topical adrenaline compared with controls. However, the eyes in this study only received medication for 7 months and a longer duration may be required to initiate changes. Similarly, Young et al $^{31}$ failed to show a statistically significant increase in myofibroblastic cell proliferation in fistulised rabbit conjunctiva pretreated with adrenaline and postulated that this may be due to the vasoconstrictive effects of adrenaline. In this study, pretreatment with other medications had increased myofibroblastic cell proliferation including artificial tears, suggesting that the preservative benzalkonium chloride may also have had a stimulatory effect.

The preservative benzalkonium chloride has been shown to be toxic to corneal cells and trabecular meshwork cells in tissue culture and in animal studies. ${ }^{1832-36}$ Adrenaline and dipivefrine have been shown to inhibit the growth of corneal cells and trabecular meshwork cells in tissue culture ${ }^{36}$ and adrenaline has been shown to have cytotoxic effects on meshwork cells and corneal epithelial cells. ${ }^{37} 38$ Williams et al ${ }^{39}$ have investigated the antiproliferative effect of several $\beta$ blockers and the preservative benzalkonium chloride on human Tenon's capsule fibroblasts in tissue culture. They demonstrated toxic effects from the commercial preparations, the pure compounds, and the preservative benzalkonium chloride.

Certain limitations apply to the use of tissue culture to assess drug effects and we cannot necessarily extrapolate directly from the in vitro situation to the in vivo case. In this model the cultured cells were exposed to the drugs continuously over a 24 hour period whereas in vivo the medications are administered twice daily over a longer period. The model does not allow for any reparative processes that may occur over several months in vivo, and any effects that may occur in vivo from interaction with non-fibroblastic cells is also not accounted for. We used cells derived from only three different subjects; however, although these numbers are small, they all appear to give similar results. Antibiotics were used in the preparation and culture of cells, but were not used during the experiments. It is possible that they may have affected the cells in culture, but control cells were treated in an identical manner and comparisons with controls are made throughout. The $\mathrm{pH}$ of our drugs in medium ranged from $7 \cdot 11$ to $7 \cdot 56$, however, we do not feel that this contributed significantly to the inhibition of proliferation. This can be illustrated by the fact that a 1:40 dilution of adrenaline base $1 \%$ had a pH of $7 \cdot 15$ in culture medium, with marked inhibition of proliferation and significant toxicity. However, at a similar $\mathrm{pH}(7 \cdot 16)$ a 1:40 dilution of adrenaline base $1 \%$ with $N$-acetyl-L-cysteine had little effect on proliferation or viability. Despite these limitations, the use of tissue culture is an accepted technique and has many advantages including the ability to control the environment and to examine individual drug effects on specific cell types.

In conclusion, our results suggest that the adrenergic medications do not directly stimulate fibroblast proliferation. Accepting that we can only make limited extrapolations from in vitro tissue culture to the in vivo situation, we can postulate one mechanism by which topical adrenergic agents may alter the conjunctival cell profile, with possible subsequent effects on the outcome of trabeculectomy. It may be that the commercial products, the pure compounds, and the preservatives are all toxic to the conjunctival cell population and this direct toxic reaction (possibly mediated by oxidation to adrenochrome in some cases) induces the inflammatory cell reaction seen in vivo. However, the induction of an inflammatory cell response may also be dependent on several other factors including the duration of treatment, the number of medications used, physical factors of the commercial formulations such as $\mathrm{pH}$ and tonicity, cumulative drug effects, toxic breakdown products, or finally the presence of other ingredients in the commercial preparations. Subsequent release of cytokines from the inflammatory cells may be responsible for enhanced fibroblast activity 
post-trabeculectomy that leads to an increased wound healing response.

The authors thank Smith and Nephew Pharmaceuticals Ltd, Allergan Pharmaceuticals (Ireland) Ltd, and Allergan Europe for kindly donating pure and commercial products; and the pharmacy manufacturing department of the Royal Hallamshire Hospital for preparing the pure compounds. C A McIntyre and R C Rees are funded by the Yorkshire Cancer Research Campaign and I A Cunliffe and this work was funded by the Royal National Institute for the Blind.

1 Cairns J. Surgical treatment of primary open angle glaucoma. Trans Ophthalmol Soc UK 1972; 92: 745-56.

2 Migdal C, Hitchings RA. Control of chronic simple glaucoma with primary medical suroical and laser treatglaucoma with primary medical surgical and laser
ment. Trans Ophthalmol Soc UK 1986; 105: 653-6.

3 Lavin MJ, Wormald RPL, Migdal CS, Hitchings RA. The influence of prior therapy on the success of trabeculectomy. Arch Ophthalmol 1990; 108: 1543-8.

4 Miller MH, Rice NSC. Trabeculectomy combined with beta irradiation for congenital glaucoma. Br 7 Ophthalmol 1991; 75: 584-90.

5 Batterbury M, Wishart PK. Is high initial aqueous outflow of benefit in trabeculectomy. Eye 1993; 7: 109-12.

6 Longstaff S, Wormald RPL, Mazover A, Hitchings RA. Glaucoma triple procedures: efficacy of intraocular pressure control and visual outcome. Ophthalmic Surg pressure control and

7 Sherwood MB, Grierson I, Millar L, Hitchings RA. Longterm morphologic effects of antiglaucoma drugs on the conjunctiva and Tenon's capsule in glaucomatous patients. Ophthalmology 1989; 96: 327-35.

8 Broadway D, Grierson I, O'Brien C, Hitchings RA. The effect of topical antiglaucoma medication on the conjunctival cell profile and the results of trabeculectomy. Invest Ophthalmol Vis Sci 1993; 34: 724.

9 Hitchings RA. Primary surgery for primary open angle glaucoma - justified or not? Br $\mathcal{f}$ Ophthalmol 1993; 77: 445-8.

10 Wilson FM. Adverse external ocular effects of topical ophthalmic medications. Surv Ophthalmol 1979; 24: 57-88.

11 Podos SM. Pharmacology of ocular drugs. 2. Epinephrine. Ophthalmology 1980; 87: 721-3.

12 Theodore J, Leibowitz HM. External ocular toxicity of dipivalyl epinephrine. Am $\mathcal{f}$ Ophthalmol 1979; 88: 1013-6.

13 Liesegang TJ. Bulbar conjunctival follicles with dipivefrin therapy. Ophthalmology 1985; 92: 228-33.

14 Jaanus SD, Pagano VT, Bartlett JD. Drugs affecting the autonomic nervous system. In: Clinical ocular pharmacology. 2nd ed. Stoneham: Butterworth, 1989: 69-148.

15 Kohn AN, Moss AP, Hargett NA, Ritch R, Smith H, Podos SM. Clinical comparison of dipivalyl epinephrine and epinephrine in the treatment of glaucoma. Am $\mathcal{F}$ Ophthalmol 1979; 87: 196-201.

16 Coleiro JA, Sigurdsson H, Lockyer JA. Follicular conjunctivitis on dipivefrin therapy for glaucoma. Eye 1988; 2: 440-2.

17 Allergan Limited. Propine prescribing information. 1993.

18 Tripathi BJ, Tripathi RC, Kolli SP. Cytotoxicity of ophthalmic preservatives on human corneal epithelium. Lens and Eye Toxicity Research 1992; 9: 361-75.

19 Wilson FM. Adverse external ocular effects of topical ophthalmic therapy: an epidemiologic, laboratory, and clinical study. Trans Am Ophthalmol Soc 1983; 81: 854-965.

20 Bartlett JD, Jaanus SD. Local anesthetics. In: Clinical ocular pharmacology. 2nd ed. Stoneham: Butterworth, 1989: 159.

21 Wright P. Cicatrizing conjunctivitis. Trans Ophthalmol Soc UK 1986; 105: 1-17.

22 Wright $P$. Squamous metaplasia of the conjunctiva as an adverse reaction to topical medication. Trans Ophthalmol Soc UK 1979; 99: 244-6.

23 Hoffer KJ. Pemphigoid related to epinephrine treatment. Am f Ophthalmol 1977; 83: 601.

24 Fiore PM, Jacobs IH, Goldberg DB. Drug induced pemphigoid. Arch Ophthalmol 1987; 105: 1660-3.

25 Pouliquen Y, Patey A, Foster CS, Goichot L, Savoldelli M. Drug induced cicatricial pemphigoid affecting the Drug induced cicatricial pemphigoid affect

26 Kristensen EB, Norn MS. Benign mucous membrane pemphigoid. Acta Ophthalmol 1974; 52: 266-81.

27 Schwab IR, Linberg JV, Gioia VM, Benson WH, Chao GM. Foreshortening of the inferior conjunctival fornix associated with chronic glaucoma medications. Ophthalmology 1992; 99: 197-202.

28 Broadway DC, Sturmer J, Grierson I, Hitchings RA. Reversal of the adverse effect of topical antiglaucoma medication on the conjunctiva prior to trabeculectomy. Invest Ophthalmol Vis Sci 1994; 35: 1914.

29 Brandt JD, Wittpenn JR, Katz LJ, Steinmann WN, Spaeth GL. Conjunctival impression cytology in Spaeth GL. Conjunctival impression cytology in patients with glaucoma using longterm top

30 Smith DL, Skuta GL, Kincaid MC, Rabbani R, Cruess DF, Kao SF. The effects of glaucoma medications on Tenon's capsule and conjunctiva in the rabbit. Ophthalmic Surg 1991; 22: 336-40.

31 Young TL, Higginbotham EJ, Xiaolian Z, Farber MD. Effects of topical glaucoma drugs on fistulized rabbit conjunctiva. Ophthalmology 1990; 97: 1423-7.

32 Stern ME, Edelhauser HF, Krebs SJ, Carney GR, Hidemen JW. A comparison of corneal epithelial and endothelial toxicity of common ophthalmic preservatives. Invest Ophthalmol Vis Sci 1983; 23: 156 .

33 Pfister RR, Burstein N. The effects of ophthalmic drugs, vehicles, and preservatives on corneal epithelium: a scanning electron microscope study. Invest Ophthalmol 1976; 15: 246-59.

34 Collin HB. Ultrastructural changes to corneal stromal cells due to ophthalmic preservatives. Acta Ophthalmol 1986; 64: 72-8.

35 Burnstein NL. Preservative cytotoxic threshold for benzalkonium chloride and chlorhexidine digluconate in cat and rabbit corneas. Invest Ophthalmol Vis Sci 1980; 19: 308-13.

36 Samples JR, Binder PS, Nayak S. The effect of epinephrine and benzalkonium chloride on cultured corneal endothelial and trabecular meshwork cells. Exp Eye Res 1989; 49: $1-12$

37 Krejci L, Harrison R. Antiglaucoma drug effects on corneal epithelium. A comparative study in tissue culture. Arch Ophthalmol 1970; 84: 766-9.

38 Tripathi BJ, Tripathi RC, Millard CB. Epinephrine induced toxicity of human trabecular cells in vitro. Lens and Eye Toxicity Research 1989; 6: 141-56.

39 Williams DE, Nguyen KD, Shapourifar-Tehrani $S$, Kitada S, Lee DA. Effects of timolol, betaxolol, and levobunolol on human Tenon's fibroblasts in tissue culture. Invest Ophthalmol Vis Sci 1992; 33: 2233-41. 